\title{
Distributed Mode Filtering Rod Fiber Amplifier With Improved Mode Stability
}

\author{
Laurila, Marko; Alkeskjold, Thomas Tanggaard; Broeng, Jes; Lægsgaard, Jesper
}

Published in:

Lasers, Sources, and Related Photonic Devices Technical Digest

Publication date:

2012

Document Version

Publisher's PDF, also known as Version of record

Link back to DTU Orbit

Citation (APA):

Laurila, M., Alkeskjold, T. T., Broeng, J., \& Lægsgaard, J. (2012). Distributed Mode Filtering Rod Fiber Amplifier With Improved Mode Stability. In Lasers, Sources, and Related Photonic Devices Technical Digest (pp.

FW5C.4). Optical Society of America.

\section{General rights}

Copyright and moral rights for the publications made accessible in the public portal are retained by the authors and/or other copyright owners and it is a condition of accessing publications that users recognise and abide by the legal requirements associated with these rights.

- Users may download and print one copy of any publication from the public portal for the purpose of private study or research.

- You may not further distribute the material or use it for any profit-making activity or commercial gain

- You may freely distribute the URL identifying the publication in the public portal

If you believe that this document breaches copyright please contact us providing details, and we will remove access to the work immediately and investigate your claim. 


\title{
Distributed Mode Filtering Rod Fiber Amplifier With Improved Mode Stability
}

\author{
Marko Laurila ${ }^{1, *}$, Thomas T. Alkeskjold ${ }^{2}$, Jes Broeng $^{2}$ and Jesper Lægsgaard ${ }^{1}$ \\ ${ }^{1}$ DTU Fotonik, Department of Photonics Engineering, Technical University of Denmark, \\ 2800 Kgs. Lyngby, Denmark, *malau@fotonik.dtu.dk \\ ${ }^{2}$ NKT Photonics, Blokken 84, 3460 Birkerød, Denmark
}

\begin{abstract}
We report 216W of average output power from a photonic crystal rod fiber amplifier. We demonstrate $44 \%$ power improvement before onset of the mode instability by operating the rod fiber in a leaky guiding regime.

OCIS codes: (060.2320) Fiber optics amplifiers and oscillators; (060.4005) Micro structured fibers.
\end{abstract}

\section{Introduction}

During the last years, photonic crystal based fiber lasers and amplifiers have undergone a massive improvement both with respect to beam quality performance and high average and peak power using fibers having very large mode area [1,2]. However, large effective area fibers often support increasing number of higher order modes and new methods to suppress them have been demonstrated $[3,4]$. Recent, experimental studies have shown a significant beam quality degradation of the fiber lasers and amplifiers when operating at high average power levels [5-7]. High average power levels can cause severe mode instabilities, occurring at some threshold level, and the level seems mostly depend on the effective area and inversion profile [6].

The causes of the mode instabilities are still under discussion. But recent development has pushed the level for mode instabilities by using rod fibers having a central doped core providing some degree of preferential gain for the fundamental mode, on the cost of reduced pump absorption [8]. In this paper, we demonstrate performance of photonic crystal bandgap rod fiber design [3] having precisely tuned Distributed-Mode-Filtering (DMF) elements. The same rod fiber design was used in a q-switched laser configuration with high efficiency and good beam quality, without indication of mode instabilities [9]. However, in those experiments the output power was limited by the pump power and the mode instability threshold level was not reached. We report the performance of the same rod fiber design in an amplifier configuration, this time with sufficient pump power available reaching the mode instability threshold level. We will further demonstrate a rod fiber design with an improved mode instability threshold level from $150 \mathrm{~W}$ to $216 \mathrm{~W}$, when the DMF rod fiber is operated in a leaky guiding regime.

\section{Experiments}

The DMF rod fibers, demonstrated in [3], have different guiding regimes and are designed to work in a specific wavelength ranges. Fig. 1(a) shows a transmission measurement of a passive DMF rod fiber, having a mode field diameter of $60 \mu \mathrm{m}$, and measured Near-Field (NF) images at two different guiding regimes, one at the leaky region $(1030 \mathrm{~nm})$ and one at the single mode region $(1060 \mathrm{~nm})$. Therefore, this DMF rod fiber has optimized operation at $1060 \mathrm{~nm}$, rather than at $1030 \mathrm{~nm}$.

In our experiments, we use a polarized seed source delivering $\sim 30 \mathrm{ps}$ pulses at $\sim 1032 \mathrm{~nm}$ with $40 \mathrm{MHz}$ repetition rate, having $0.25 \mathrm{~nm}$ spectral width and max average output power of $1.7 \mathrm{~W}$. The DMF rod fibers are pumped in counter-propagating direction with a pump module delivering up to $600 \mathrm{~W}$ of pump power $(976 \mathrm{~nm}, 400 \mu \mathrm{m}$, $0.22 \mathrm{NA}$ ). We single-pass both the pump and the signal and use a CCD camera, at the output side, to verify the quality of the output beam (frame rate $\sim 20-30 \mathrm{~Hz}$ ). 


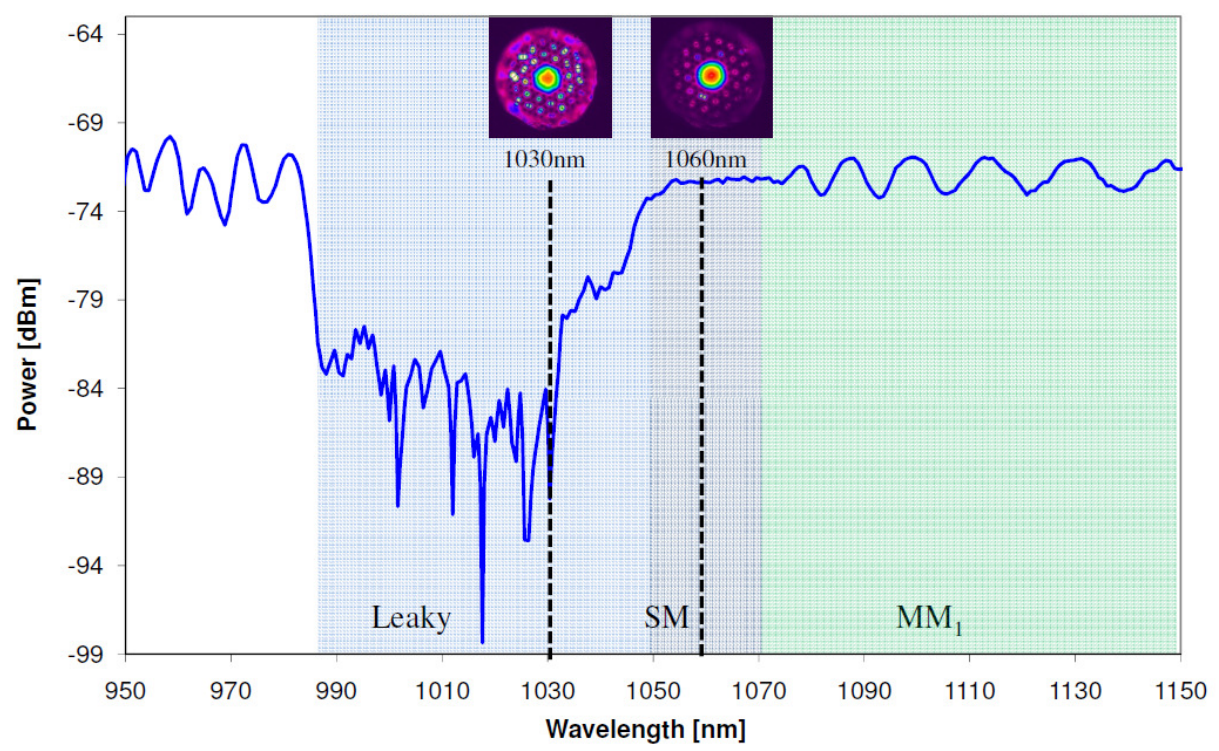

Fig. 1. (a) Transmission measured of a passive DMF rod fiber having a mode field diameter of $60 \mu \mathrm{m}$. Interference patterns, in the spectrum indicate multimode behavior, a dip the leaky regime, and the single mode region can be identified between 1050nm - 1070nm. Measured near field images show the guiding dynamics of the DMF rod fiber.

We use two different ytterbium-doped double-clad DMF rod fibers in an amplifier configuration. The DMF rod fibers were manufactured to be single mode in two different wavelength regions, one at 1030-1045nm, referred to as "DMF1030" and the other 1050-1070nm, referred to as "DMF1064". The DMF rod fibers have a core diameter of $\sim 85 \mu \mathrm{m}$, having an estimated NA $\sim 0.01$ and a pump cladding of $267 \mu \mathrm{m}$ with $\sim 0.6 \mathrm{NA}$. The DMF rod fibers are $90 \mathrm{~cm}$ long, having pump absorption of $\sim 27 \mathrm{~dB} / \mathrm{m}$ at $976 \mathrm{~nm}$ and both of the ends are prepared with AR-coated end caps.

Fig. 2 shows slope effiencies of both DMF rod fibers and the output spectra at the maximum output powers. The DMF1030 has a slope efficiency of $71 \%$ and a maximum available output power of $150 \mathrm{~W}$ before the onset of the mode instability. The spectrum was recorded at $150 \mathrm{~W}$ of output power with FWHM of $\sim 0.3 \mathrm{~nm}$. The DMF1064 has a slope efficiency of $75 \%$ but the maximum available output power is much higher than for the DMF1030. The DMF1064 shows significant mode stability improvement and the onset of the mode instability is found at $216 \mathrm{~W}$. The recorded spectrum, in Fig. 2(b) at 216W of output power, has $\sim 0.3 \mathrm{~nm}$ of FWHM.

(a)

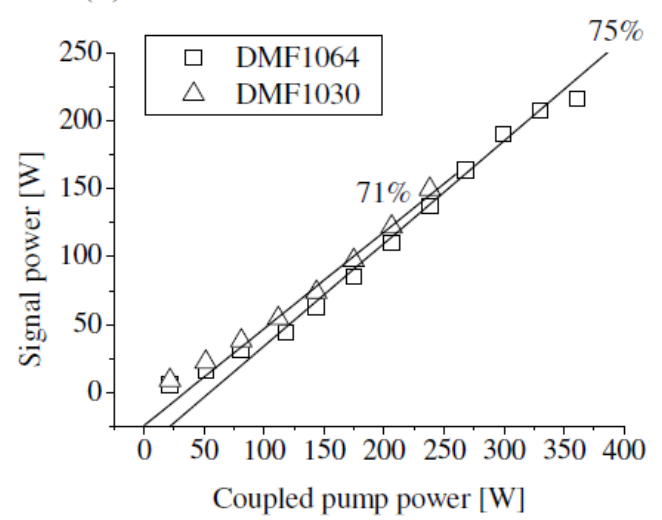

(b)

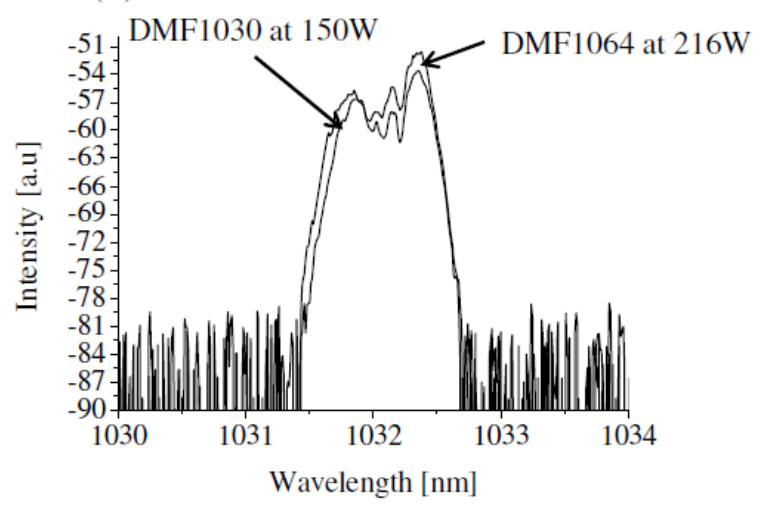

Fig. 2. (a) Slope efficiency measurement of the DMF1030 and the DMF1064. (b) Recorded output spectra at the maximum output powers.

When the DMF1064 is used with a 1030nm signal it operates in the leaky regime, where the fundamental mode is coupled to the DMF elements and has high confinement loss. At low output power levels $(<50 \mathrm{~W})$, the core mode appears to be leaky with high amount of cladding light, but becomes more confined at higher output power levels 
( $>80 \mathrm{~W}$ ), as shown in Fig. 3(b). This can also be observed from the signal core to cladding ratio, shown in Fig. 3(a), which shows that the core light increases from $60 \%$ to $90 \%$ with increasing power. The increased confinement loss at low power levels also decreases slope efficiency at low power levels, as shown in Fig. 2(a).

This indicates that the confinement loss decreases with increasing output power levels. This could be caused by a thermally introduced refractive index change of the core. As the DMF1064 is operated in the leaky regime at low power levels and as the power is increased, the thermal load will raise the refractive index of the core and the DMF filtering effect is blue shifted. This can be seen from Fig. 1 as a blue shift of the transmission spectrum. This blue shift will provide better confinement for the fundamental mode.

(a)

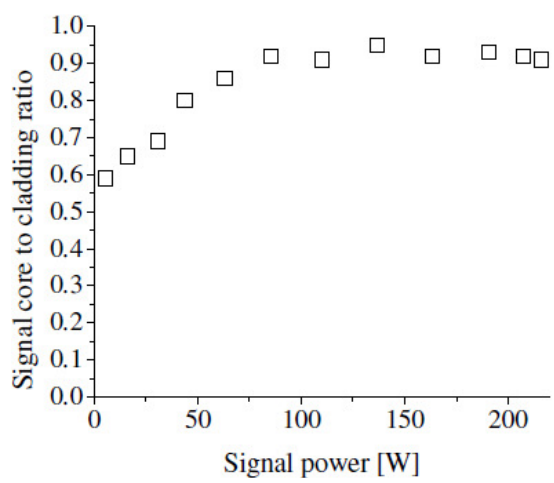

(b)
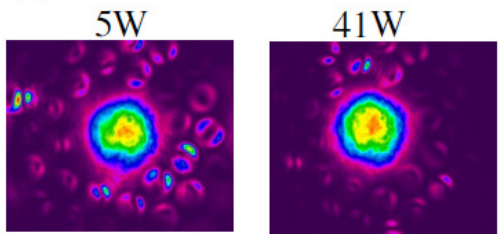

$80 \mathrm{~W}$
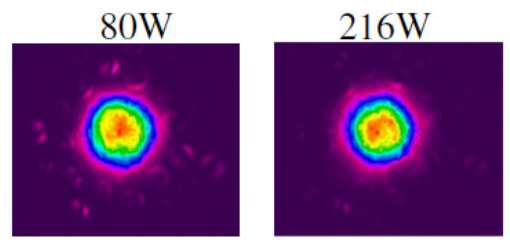

Fig. 3. (a) Measured signal core to cladding ratio of the DMF1064. (b) Recorded evolution of NR image quality at different signal output powers

\section{Conclusions}

(DMF1064).

We have demonstrated a high power fiber amplifier utilizing the Distributed-Mode-Filtering (DMF) rod fiber design having improved mode stability up to $216 \mathrm{~W}$ of average output power. We reported a mode instability threshold output power level improvement of $44 \%$ by operating the DMF rod fiber in the leaky regime. We speculate that the change of the guiding regimes is caused by a thermally introduced refractive index change of the core. We observe the change in the confinement by measuring the signal core to cladding ratio and near fields at different output power levels.

\section{Acknowledgements}

The project is supported with funding from the EU FP7 project LIFT (CP- IP 228587-1- LIFT) and The Danish Council for Independent Research and Technology and Production Sciences (FTP).

\section{References}

[1] J. Limpert, O. Schmidt, J. Rothhardt, F. Röser, T. Schreiber, A. Tünnermann, S. Ermeneux, P. Yvernault and F. Salin, "Extended singlemode photonic crystal fiber lasers," Opt. Express 14, 2715-2720 (2006).

[2] C. D. Brooks and F. D. Teodoro, “Multimegawatt peak-power, single-transverse-mode operation of a 100 $\mu \mathrm{m}$ core diameter, Yb-doped rodlike photonic crystal fiber amplifier", Applied Physics Letters 89 (2006).

[3] T. T. Alkeskjold, M. Laurila, L. Scolari, and J. Broeng, "Single-mode ytterbium-doped large-mode-area photonic bandgap rod fiber amplifier," Opt. Express 19, 7398-7409 (2011).

[4] F. Jansen, F. Stutzki, H. Otto, M. Baumgartl, C. Jauregui, J. Limpert, and A. Tünnermann, "The influence of index-depressions in corepumped Yb-doped large pitch fibers," Opt. Express 18, 26834-26842 (2010).

[5] A. V. Smith and J. J. Smith, "Mode instability in high power fiber amplifiers," Opt. Express 19, 10180-10192 (2011).

[6] T. Eidam, C. Wirth, C. Jauregui, F. Stutzki, F. Jansen, H. Otto, O. Schmidt, T. Schreiber, J. Limpert, and A. Tünnermann, "Experimental observations of the threshold-like onset of mode instabilities in high power fiber amplifiers," Opt. Express 19, 13218-13224 (2011).

[7] C. Jauregui, T. Eidam, J. Limpert, and A. Tünnermann, "Impact of modal interference on the beam quality of high-power fiber amplifiers," Opt. Express 19, 3258-3271 (2011).

[8] F. Stutzki, F. Jansen, T. Eidam, A. Steinmetz, C. Jauregui, J. Limpert, and A. Tünnermann, "High average power large-pitch fiber amplifier with robust single-mode operation," Opt. Lett. 36, 689-691 (2011)

[9] M. Laurila, J. Saby, T. T. Alkeskjold, L. Scolari, B. Cocquelin, F. Salin, J. Broeng, and J. Lægsgaard, "Q-switching and efficient harmonic generation from a single-mode LMA photonic bandgap rod fiber laser," Opt. Express 19, 10824-10833 (2011). 